\title{
AN INVESTIGATION OF FASHION DESIGN AND PATTERN MAKING OF LADIES' JACKETS WITH DIFFERENT TYPES OF SLEEVES
}

\author{
Zlatina Kazlacheva, Petya Dineva \& Julieta llieva \\ Faculty of Technics and Technologies, Trakia University, Bulgaria \\ Graf Ignatiev 38, 8600 Yambol, Bulgaria \\ e-mail: zlatinka.kazlacheva@trakia-uni.bg, petya.dineva@trakia-uni.bg, \\ zhulieta.ilieva@trakia-uni.bg
}

\begin{abstract}
The patterns of raglan, semi raglan, kimono, and dropped shoulder sleeves are made on one and the same constructional bases. In the constructional base the front and back in the underarm there are parts which have to be set to the both - the bodice and the sleeve. For the front and the back that is possible if the sleeve and a part of the bodice are separated by a design constructional seam. The type and design of the sleeve depends by the directions of the design constructional seam. If the seam joins the underarm and the neckline, or area around the neckline the type of sleeve is raglan. If the seam connects the underarm and the shoulder the type of sleeve is semi raglan. The type of the sleeve is kimono if the design constructional seam divides the bodice or the sleeve. In the dropped shoulder sleeve design constructional seam is located under the shoulder. The use of the main design principles, the possibilities for combinations between the four types of sleeves and the design with application of $3 D$ elements are investigated. Raglan, semi raglan, kimono and dropped shoulder sleeves can be combined each other. In combined sleeves only one of seams which define the types of the sleeves is with decorative constructional function. The other ones have only decorative function. Design constructional seams which define the types of the sleeves can be used as contours of location or fixation of all types of 3D elements: pleats, goffers, flounces, tucks gathers, and draperies. The results of the investigation of application of the main design principles, combinations between different types of sleeves and possibility for the use of $3 D$ elements facilitate the process of fashion design and pattern making and gives opportunity for variety of models.
\end{abstract}

Keywords: fashion design, pattern making, sleeve, raglan, semi raglan, kimono, dropped shoulder sleeve, 3D elements, lady's jacket.

\section{INTRODUCTION}

Fashion design and pattern making of ladies' jackets with sleeves which are different to the traditional one piece and two pieces ones are presented in the paper. The different types of sleeves are raglan, semi raglan, kimono, and dropped shoulder ones. The patterns of these types of sleeves are made on one and the same constructional bases [3], shown in Figure 1. Figure 1 presents the constructional bases for the front and the back. It is seen that for the front and back in the underarm there are parts which have to be set to the both - the bodice and the sleeve. For the front and the back that is possible if the sleeve and a part of the bodice are separated by a design constructional seam. The type and design of the sleeve depends by the directions of the design constructional seam. If the seam joins the underarm and the neckline, or area around the neckline the type of sleeve is raglan. If the seam connects the underarm and the shoulder the type of sleeve is semi raglan. The type of the sleeve is kimono if the design constructional seam divides the bodice or the sleeve. In the dropped shoulder sleeve design constructional seam is located under the shoulder.

The use of the main design principles [1], the possibilities for combinations between the four types of sleeves and the design with application of 3D elements [4] are investigated. 


\section{ARTTIE $Y$}

Ipplied Resseirlores in Technics, Technologies and Educration Journal of the Faculty of Technics and Technologies, Trakia University https://sites.google.com/a/trakia-uni.bg/artte/
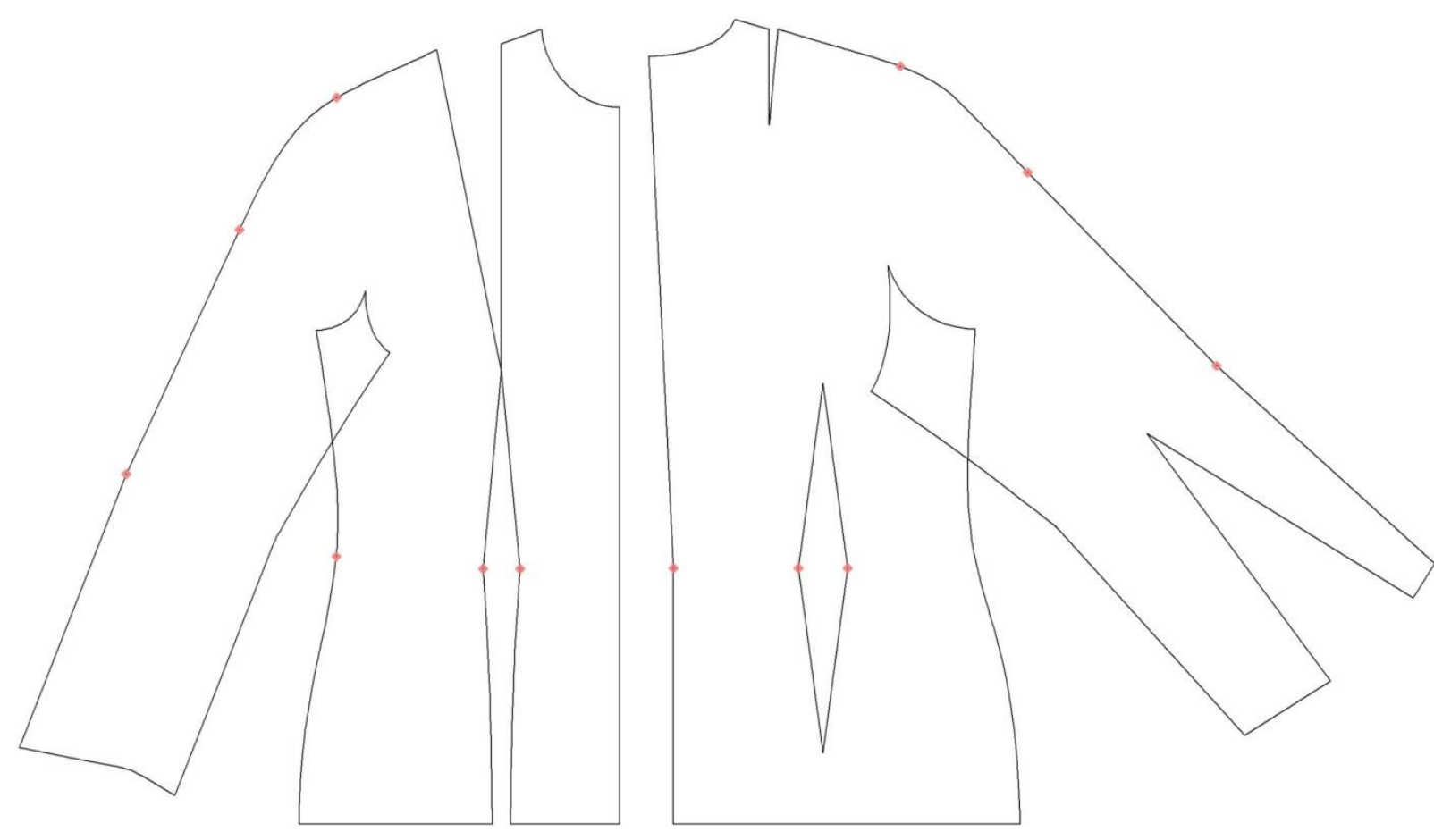

Figure 1.

Constructional bases for pattern making of raglan, semi raglan, kimono and dropped shoulder sleeves

\section{FASHION DESIGN AND PATTERN MAKING OF RAGLAN, SEMI RAGLAN, KIMONO AND DROPPED SHOULDER SLEEVES}

Figure 2 presents design and pattern making of a lady's jacket with a classic form of raglan sleeves or raglan form designed with a curved line. According to principle of the similarity, one of the main design principles, the raglan form is connected with the curved form of the neckline and design constructional seams which transform bust and waist darts.

Figure 3 shows fashion design and pattern making of a lady's jacket with raglan form designed by two straight lines with roundness. According to the design principle of similarity the form of the neckline is similar to the raglan. The angular forms of the raglan sleeves and the neckline are balanced with contrasted curved form of the design constructional seams which transform bust and waist darts.

The leading design principle is the symmetry. [1, 2] Fashion design and pattern making of the model of ladies' jackets, shown in Figures 4, 5, 6, 7 and 8, are examples for the use of bilateral, radial and translated symmetry in design of raglan and semi raglan sleeves.

In the lady's jacket, presented in Figure 4, the raglan form is designed with a line which combines a curved and a straight part. Using the symmetry of translation the raglan forms of the front and the back are translated in the design of the decorative constructional seams which transform bust and waist darts.

Figure 5 presents a lady's jacket with semi raglan sleeves. The semi raglan form is designed with a curved line. Using the bilateral or mirror symmetry the form of the neckline is a mirror image of the semi raglan form. 


\section{AR'TIE

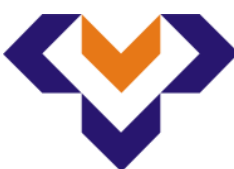 \\ Ipplied Resseirlohes in Technics, Technologies and Eductition \\ Journal of the Faculty of Technics and Technologies, Trakia University https://sites.google.com/a/trakia-uni.bg/artte/}

In the lady's jacket, shown in Figure 6, the semi raglan form is designed with a curved line. Similarly to the model in Figure 4 in the upper variant of pattern making using the symmetry of translation the semi raglan forms of the front and the back are translated in the design of the decorative constructional seams which transform bust and waist darts. In the down variant of pattern making is used radial symmetry.

In the model of a lady's jacket, presented in Figure 7, the principle of similarity is used not only in the mirror symmetry which is seen in the forms of the semi raglan sleeves and the neckline. The similarity is use in the design of the decorative constructional seams which transform bust and waist dart. The forms of these seams are in supple connection with semi raglan forms.

Figure 8 shows fashion design and pattern making of a lady's jacket with semi raglan sleeves which form are a result of radial symmetry to the neckline.

Figure 9 presents a classical design and pattern making of a lady's jacket with kimono sleeves. The form of the sleeves is a result of the decorative constructional seams in the front and the back which transform bust and waist darts in the bodice. In the front and the back design constructional seams start by the underarm.

Fashion design and pattern making of a lady's jacket with dropped shoulder sleeves [5] are shown in Figure 10. In the model the form of the sleeves is result from the use of light curved lines.

Figures 11, 12, 13, and 14 present models of ladies jacket with combined sleeves, mixed kimono, raglan, semi raglan ad dropped shoulder sleeves.

Figure 11 shows fashion design and pattern making model of a lady's jacket with sleeves, combinations from kimono and dropped shoulder ones. The dropped shoulder form is designed with straight lines. In this case the dropped shoulder seams have only decorative function. [5]

Figure 12 presents design and pattern making of a lady's jacket with sleeves which combine raglan, kimono and dropped shoulder ones. In this case the raglan and dropped shoulder seams have only decorative function.

Figure 13 presents fashion design and pattern making of a lady's jacket with sleeves which combine semi raglan, kimono and dropped shoulder ones. In this case the semi raglan and dropped shoulder seams have only decorative function.

The model of a lady's jacket, shown in Figure 14, is with sleeves which combine kimono, semi raglan and raglan forms. In this case the kimono form is a result from seams which are situated in the front and the back of the sleeve and start by the underarm. The raglan seams have only decorative function. The semi raglan form is a result of intersection of raglan and bodice decorative constructional seams.

Figures $15,16,17,18$, and 19 present possibility of design of these types of sleeves in combinations with $3 d$ elements. [4]

Figure 15 presents fashion design and pattern making of a lady's jacket with bi-sided pleats in the neckline, located in the raglan decorative constructional seams. The same way of pattern making can be used in design of sleeves with flounces.

Figure 16 shows fashion design and pattern making of a lady's jacket with bi-sided tucks, fixed in the raglan decorative constructional seams.

Figure 17 presents fashion design and pattern making of a lady's jacket with gathers, fixed in the raglan decorative constructional seams. The gathers in the model transform the bi-sided tucks in the lady's jacket shown in Figure 16.

Figure 18 shows fashion design and pattern making of a lady's jacket in which dropped shoulder sleeves are designed with goffers.

Figure 19 presents fashion design and pattern making of a lady's jacket with free draperies, fixed in the semi raglan decorative constructional seams. 


\section{IRTIIE}
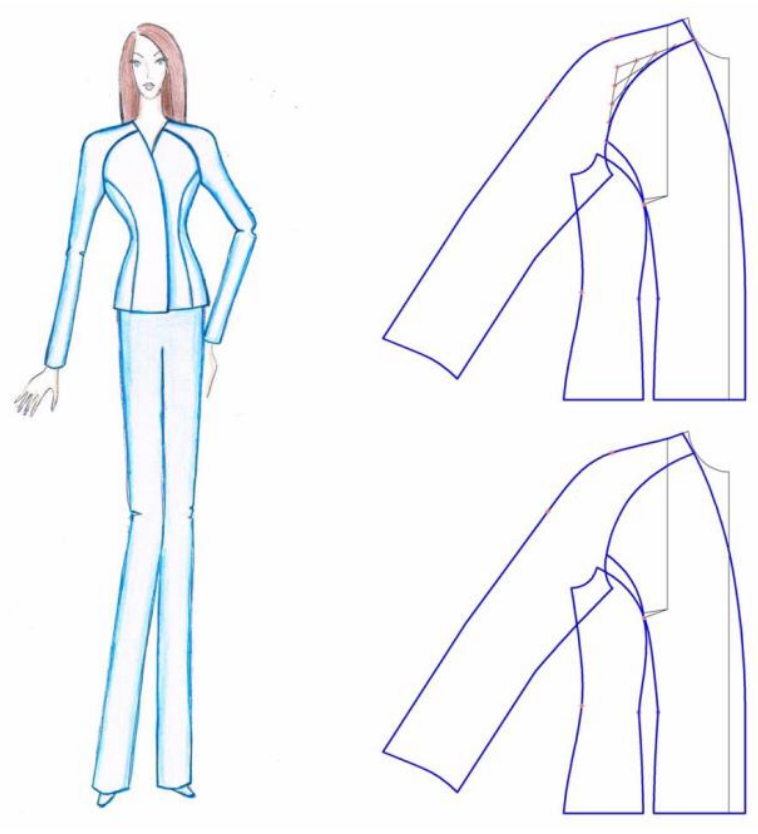

Figure 2. Raglan sleeve.

Raglan form designed with a curve
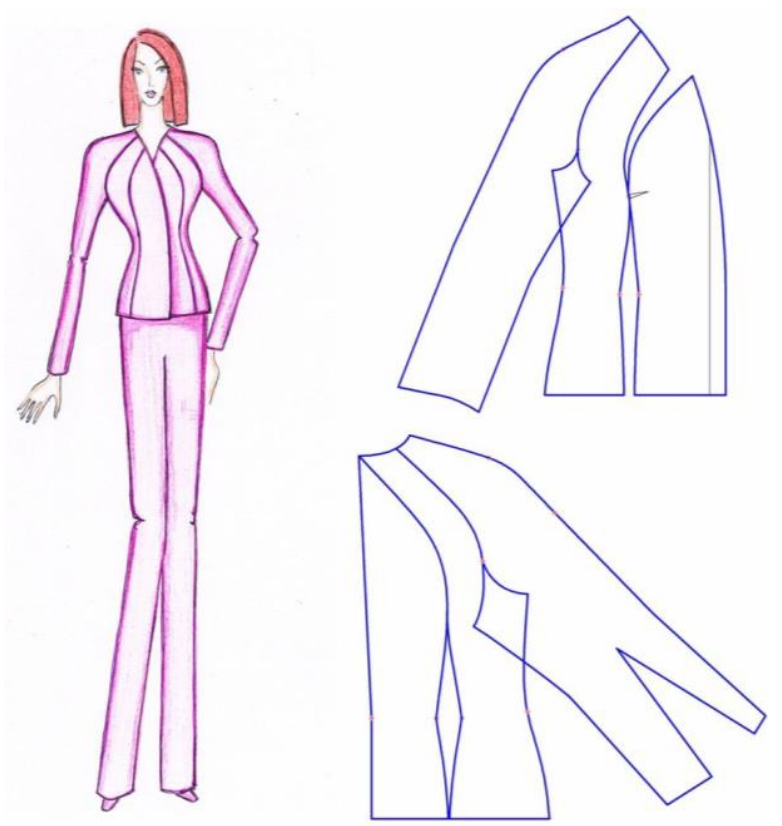

Figure 4. Raglan sleeve. Raglan form designed with a combined curved and straight line which is translated in the bodice decorative constructional seam
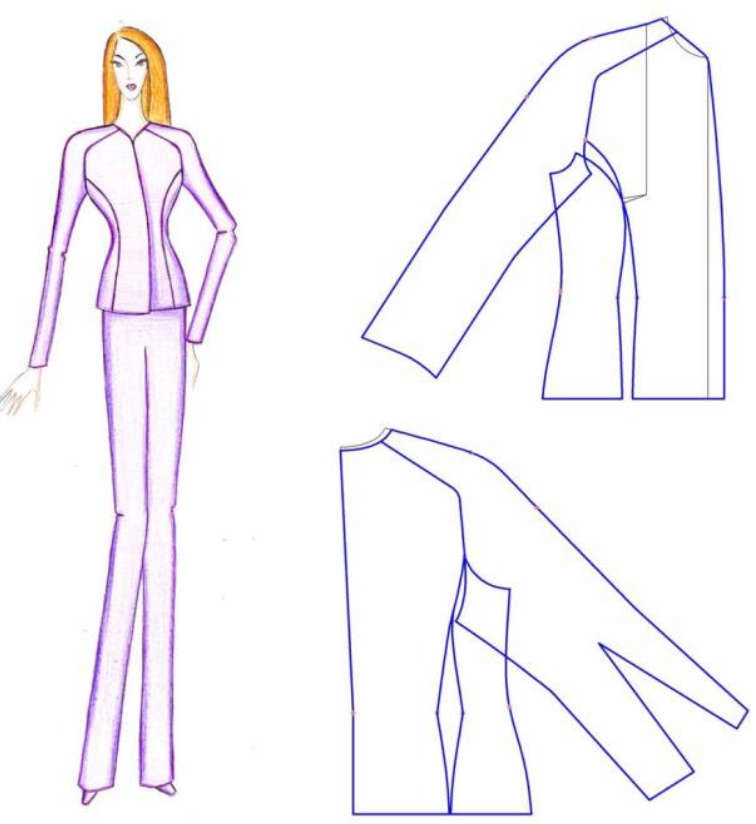

Figure 3. Raglan sleeve.

Raglan form designed with two straight lines with roundness
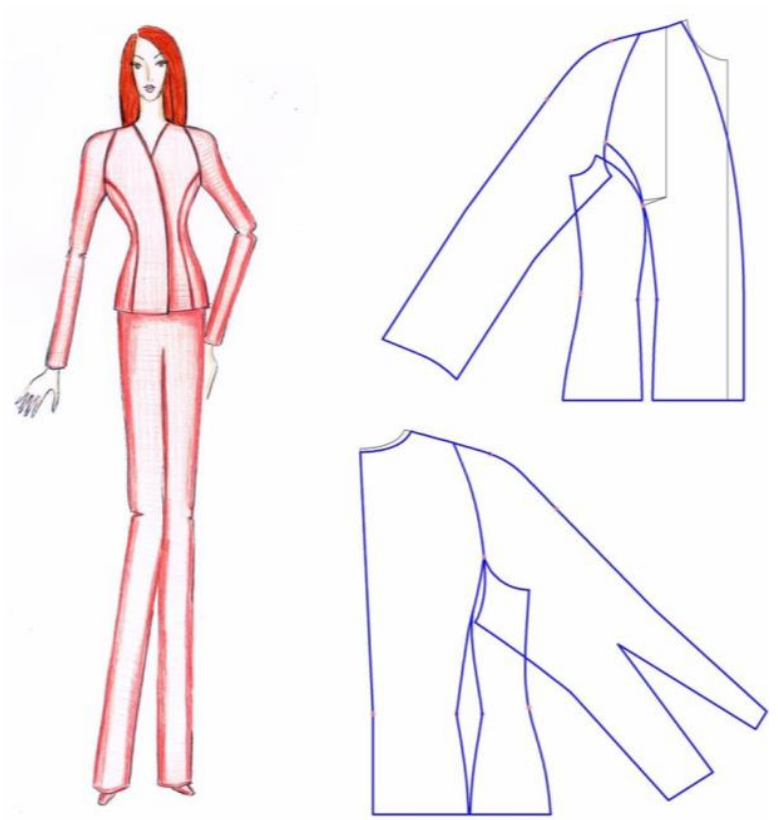

Figure 5. Semi raglan sleeve. Semi raglan form designed with a curve. The neckline is a mirror image of the semi raglan seam 

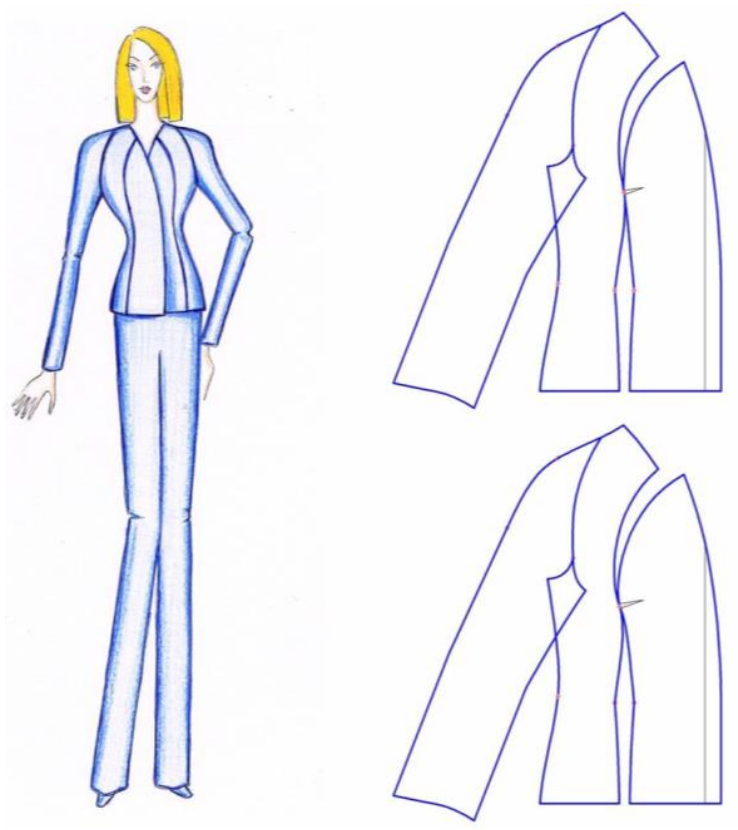

Figure 6. Semi raglan sleeve. Semi raglan form designed with a curve which is connected with the bodice decorative constructional seam on the base translated or radial symmetry
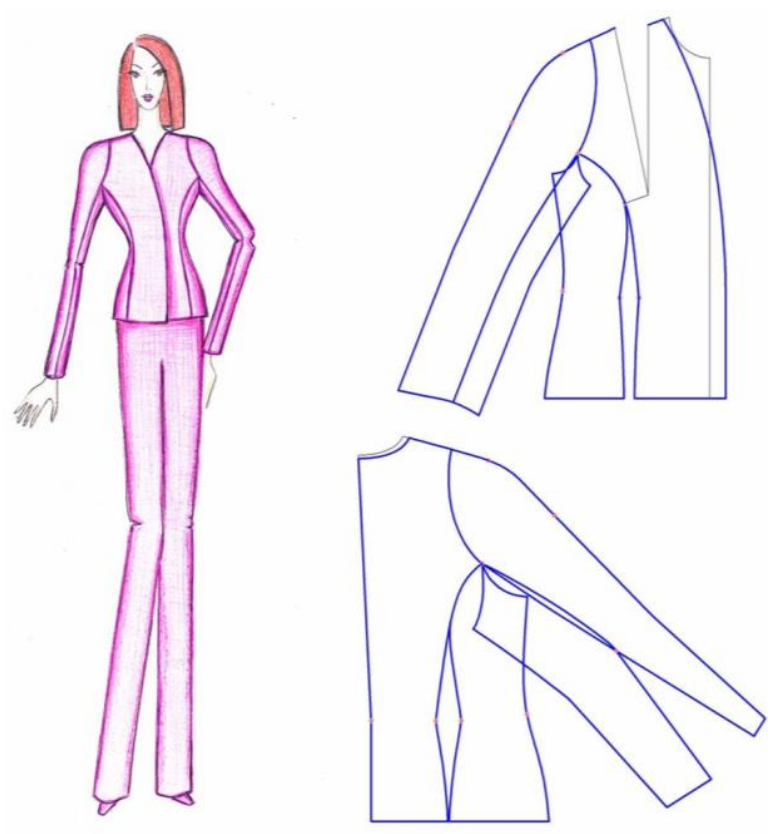

Figure 8. Semi raglan sleeve. Semi raglan seam and the neckline connected on the base radial symmetry
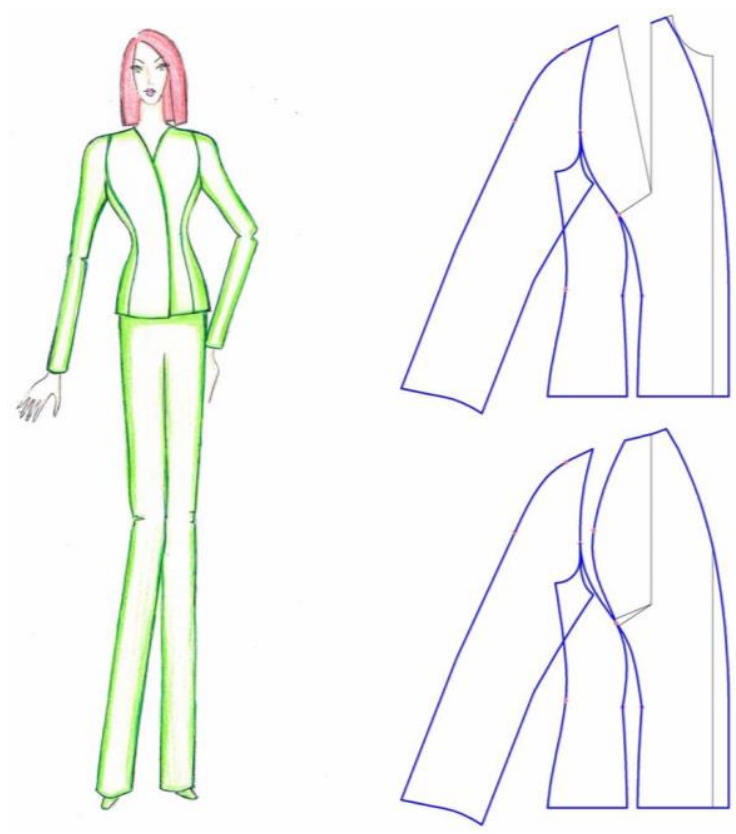

Figure 7. Semi raglan sleeve. Semi raglan form designed with a curve which is in supple connection with the bodice decorative constructional seam
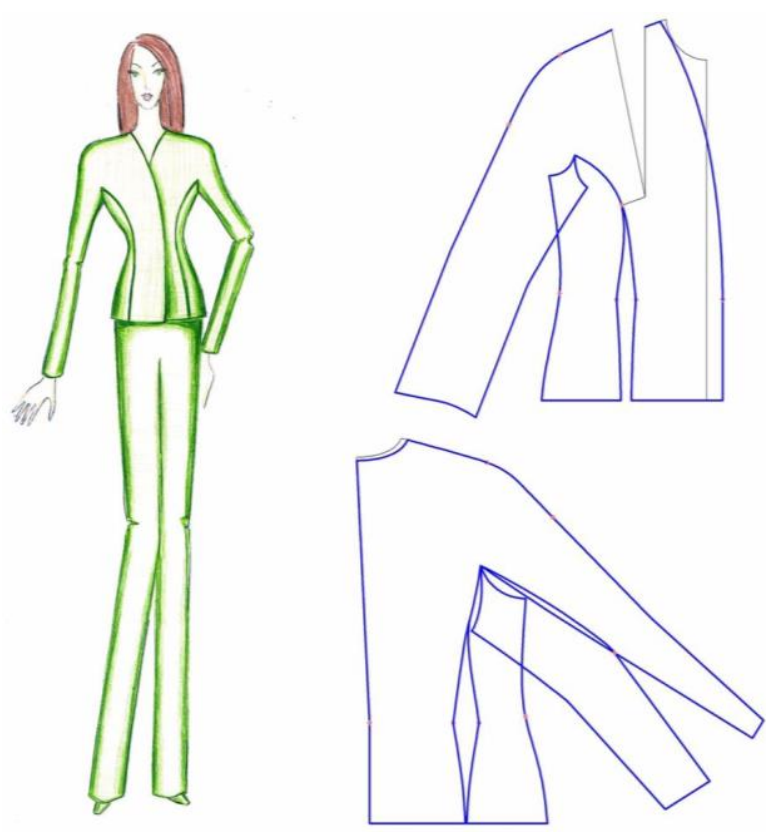

Figure 9. Kimono sleeve.

The sleeve form is result of bodice decorative constructional seams 

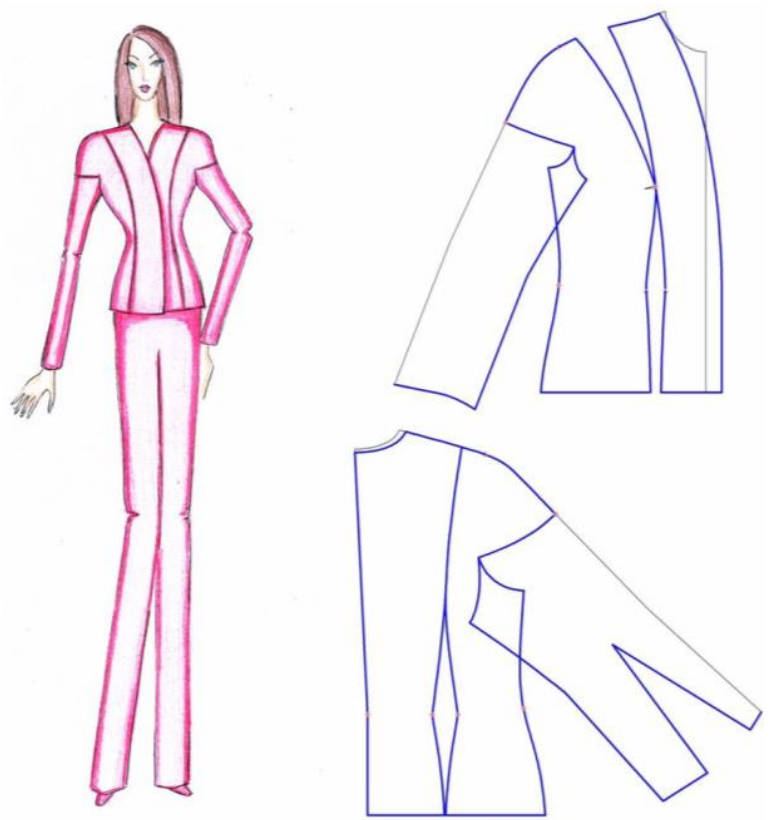

Figure 10.

Dropped shoulder sleeve. The sleeve form is result of light curved lines
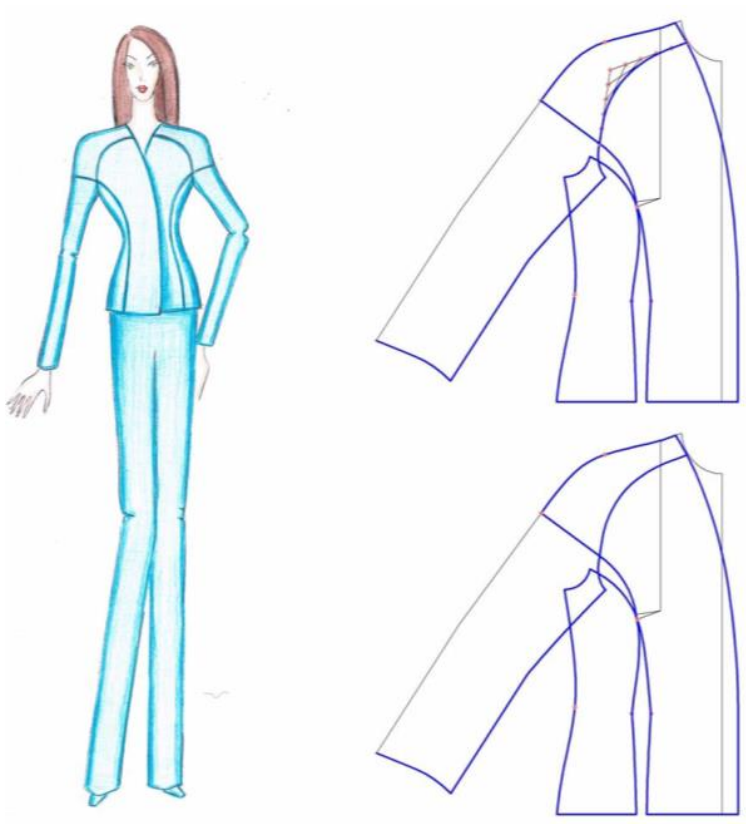

Figure 12

Sleeves, combined kimono, raglan and dropped shoulder forms
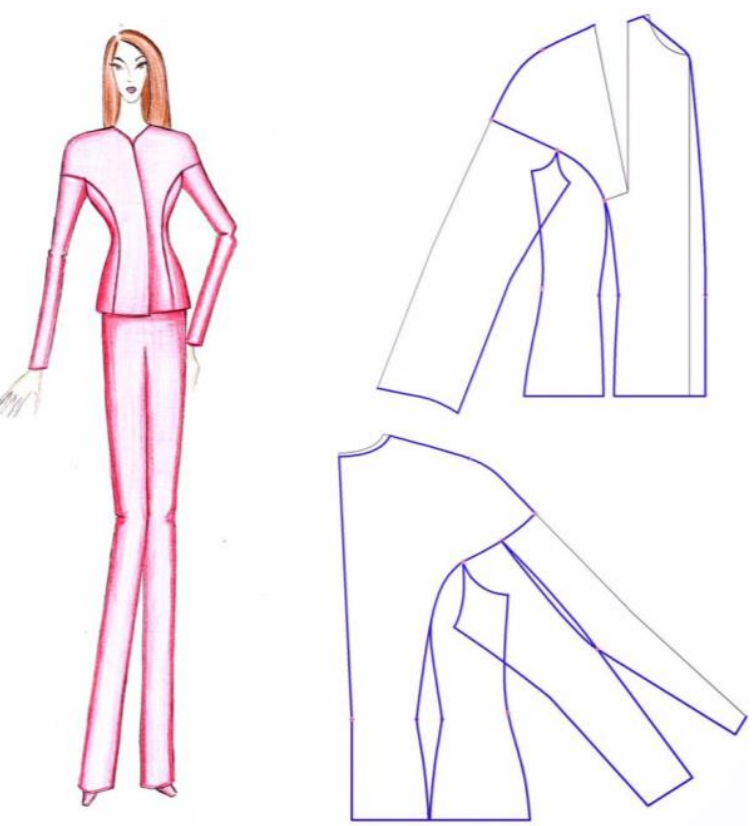

Figure 11.

Sleeves, combined kimono and dropped shoulder forms
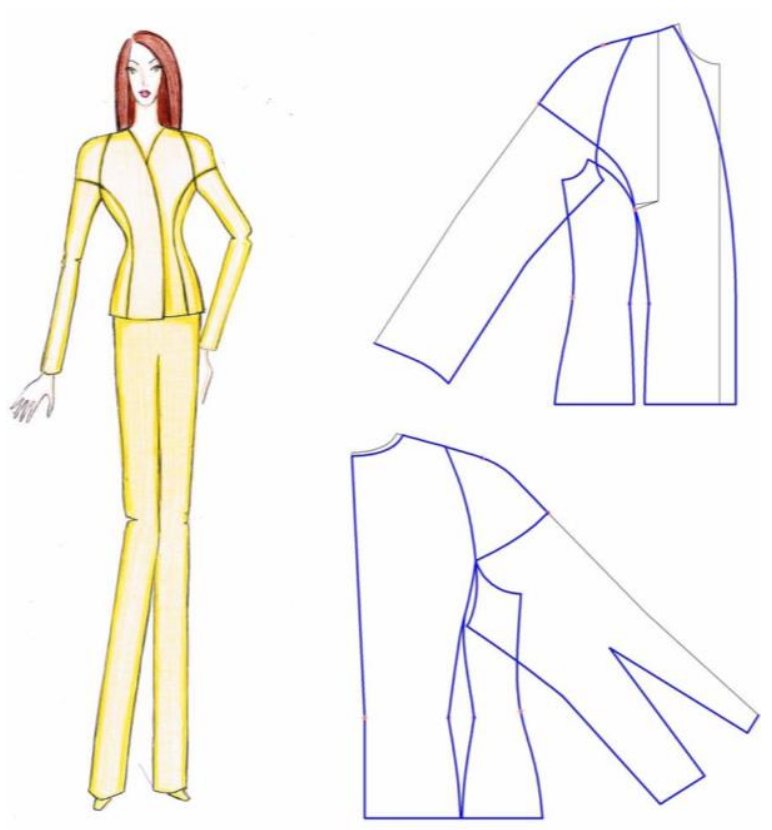

Figure 13.

Sleeves, combined kimono, semi raglan and dropped shoulder forms 

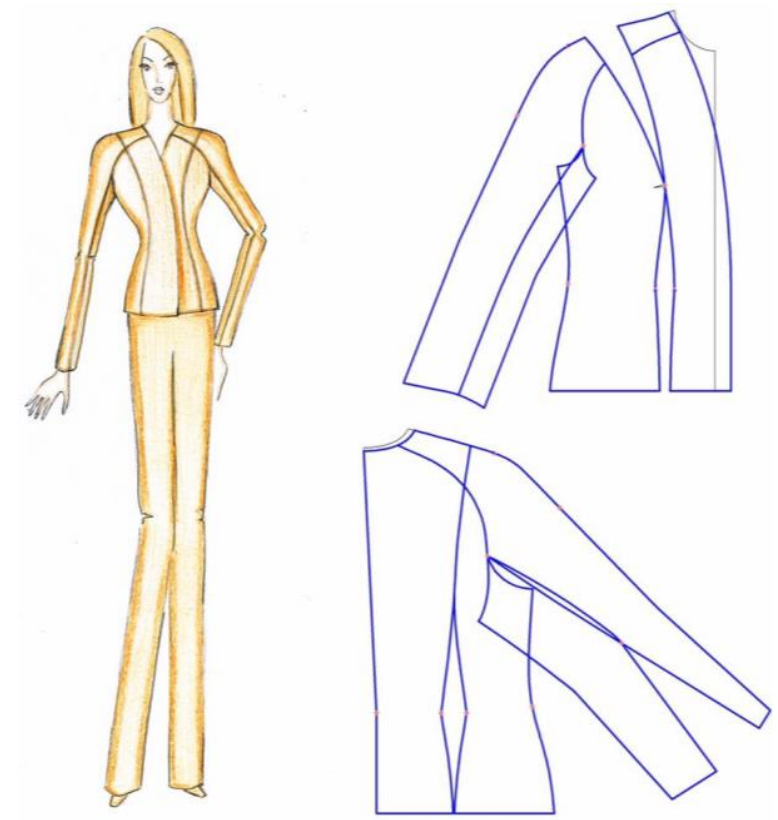

Figure 14.

Sleeves, combined kimono, raglan and semi raglan forms
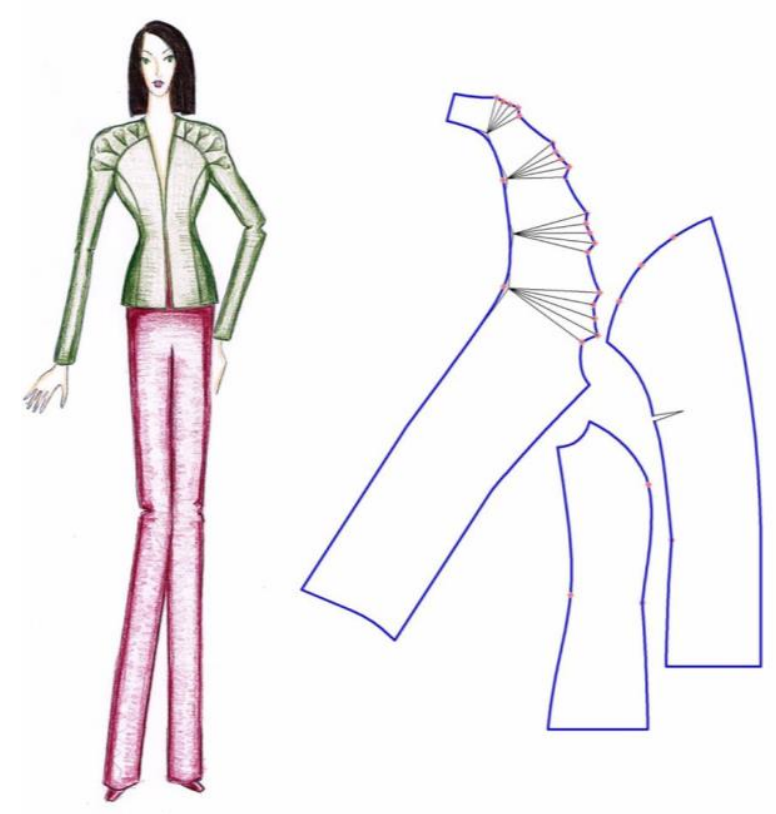

Figure 16.

Bi-sided tucks, fixed in the raglan seams

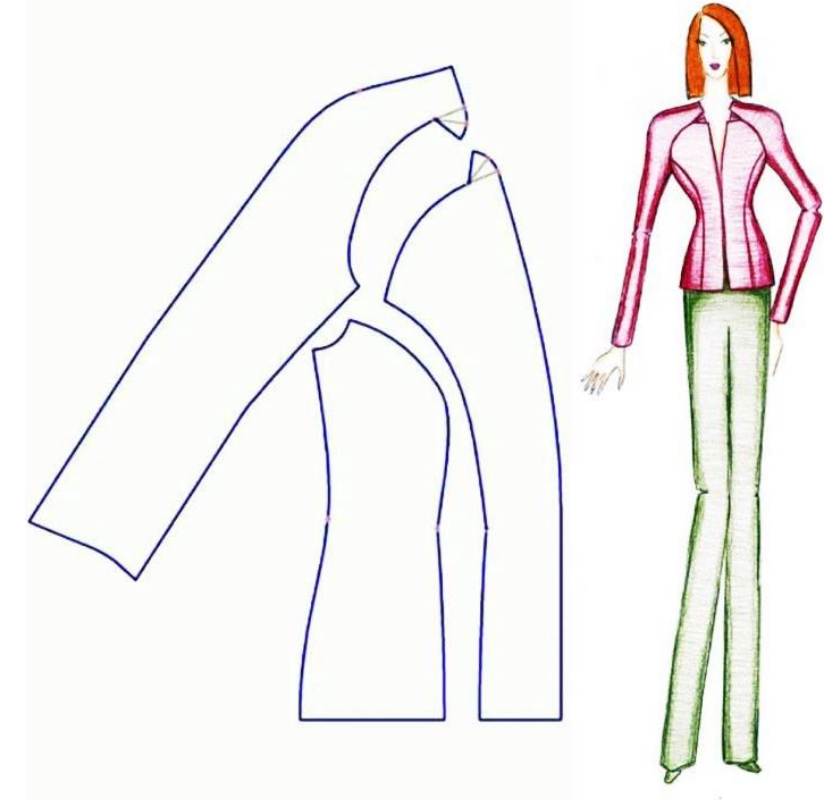

Figure 15.

Bi-sided pleats, located in the raglan seams
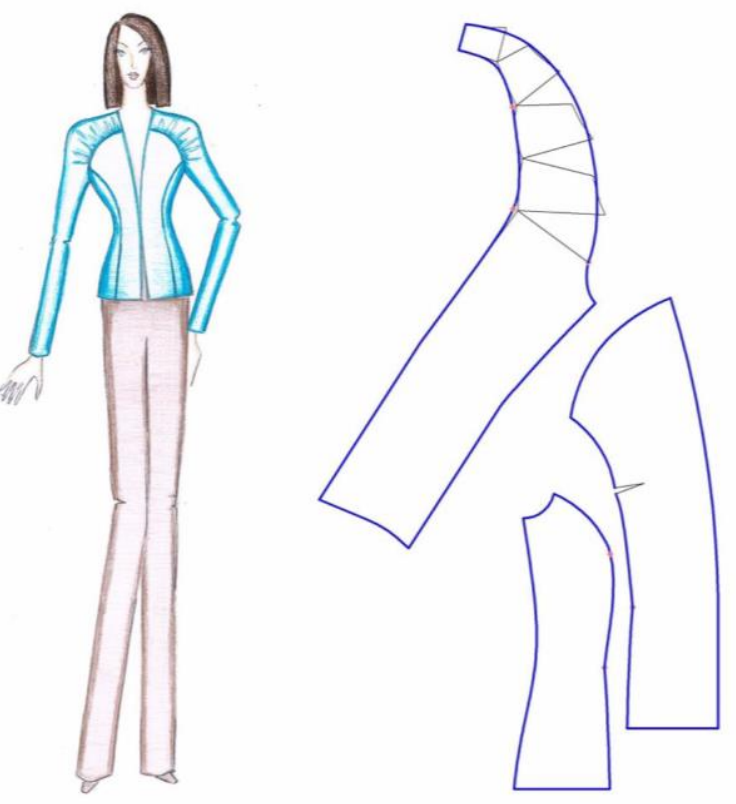

Figure 17.

Gathers, fixed in the raglan seams

IRTIIE Vol. 4, No. 4, 2016 ISSN 1314-8788 (print), ISSN 1314-8796 (online), doi: 10.15547/artte.2016.04.001 

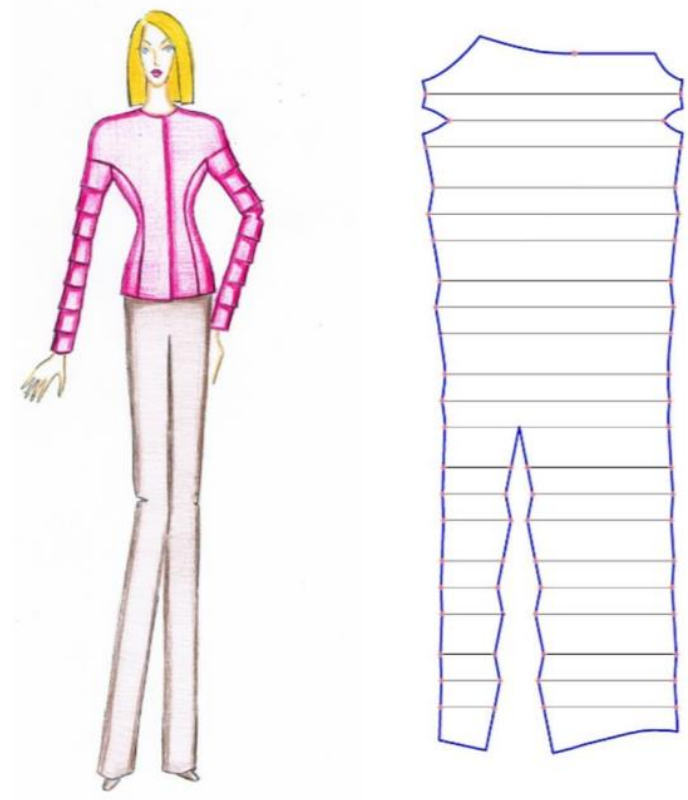

Figure 18

Dropped shoulder sleeves with goffers
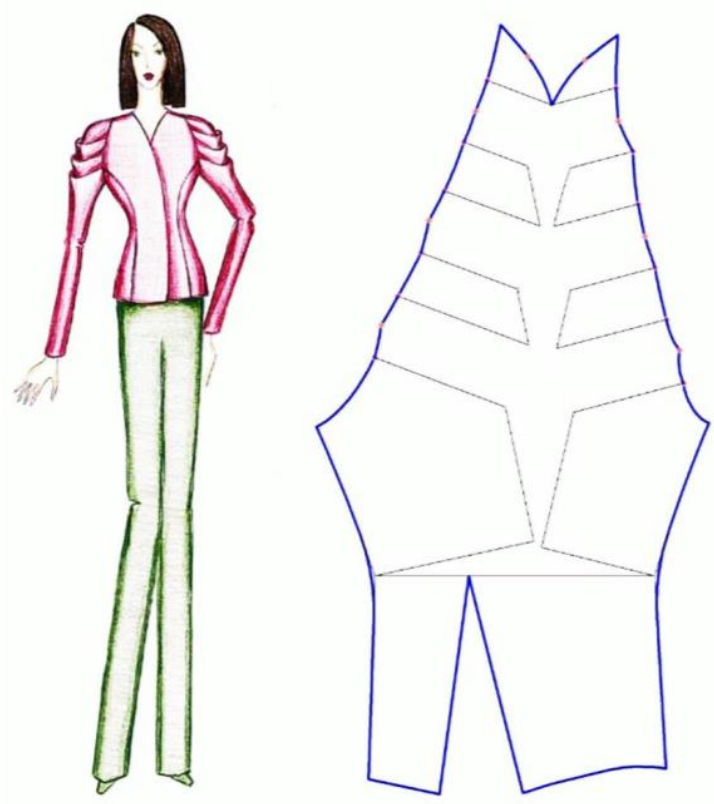

Figure 19.

Free draperies, fixed in the semi raglan seams

\section{CONCLUSION}

- The raglan, semi raglan, kimono and dropped shoulder forms can be mixed each other in combined sleeves. The combination between two, three or the four types of sleeves are possible. In the combined sleeves only one of seams which define the types of the sleeves is with decorative constructional function. The other ones have only decorative function.

- Design constructional seams which define the types of the sleeves can be used as contours of location or fixation of all types of 3D elements: pleats, goffers, flounces, tucks gathers, and draperies.

- The results of the presented investigation of application of the main design principles, combinations between different types of sleeves and possibility for the use of 3D elements facilitate the process of fashion design and pattern making and gives opportunity for variety of models.

\section{ACKNOWLEDGEMENTS}

The work is supported by the scientific project 2.FTT/ 2016 'Investigation of the Fashion Design and Pattern making of 3D Elements in Ladies' Clothing' funded by the Faculty of Technics and Technologies of Yambol, Trakia University of Stara Zagora, and the Fund of the National budget for scientific research in higher education in Bulgaria. 


\section{IRTIL $<>$}

Ipplied Resseirlohes in Technics, Technologies and Educration Journal of the Faculty of Technics and Technologies, Trakia University https://sites.google.com/a/trakia-uni.bg/artte/

\section{REFERENCES}

[1] Jirousek Ch. (1995). Art, Design and Visual Thinking. Cornell University. http://char.txa.cornell.edu/.

[2] Kazlacheva Z. (2013). Symmetry in Nature and Symmetry in Fashion Design. EMIT Economics Management Information Technology, Vol. 1, No. 4, 2013, pp. 267-276; http://www.emit.kcbor.net/Kompletni\%20casopisi/EMIT\%20Vol1\%20No4.pdf\#page=68.

[3] Kazlacheva Z. (2013). Pattern Making of Ladies' Jackets with Padded Shoulders. ARTTE Applied Researches in Technics, Technologies and Education, Vol. 1, No. 1, 2013, pp. 14-20; https://sites.google.com/a/trakia-uni.bg/artte/articles/artte-vol-1-no-1.

[4] Kazlacheva Z. (2015). Variants of a Lady's Dress with 3D Transformations. Journal of Textile Science and Engineering, Vol. 5, No. 3, 2015: 198. doi:10.4172/21658064.1000198; https://www.omicsgroup.org/journals/variants-of-a-ladys-dress-with-3dtransformations-2165-8064-1000198.php?aid=57046.

[5] Kazlacheva Z. (2016). Variants of Ladies' Jackets with Dropped Shoulders Sleeves. ARTTE Applied Researches in Technics, Technologies and Education, Vol. 4, No. 1, 2016, pp. 64-71. doi: 10.15547/artte.2016.01.007; https://sites.google.com/a/trakiauni.bg/artte/articles/artte-vol-4-no-1. 